\title{
Towards A Smart Learning Environment for Smart City Governance
}

\author{
Rawad Hammad \\ Software Engineering Research \\ Group, Faculty of Environment and \\ Technology, University of West of \\ England (UWE), Bristol, UK. \\ 00441173287856 \\ Rawad.Hammad@uwe.ac.uk
}

\author{
David Ludlow \\ Centre for Sustainable Planning and \\ Environments, Faculty of Environment \\ and Technology, University of West of \\ England (UWE), Bristol, UK. \\ 00447818095327 \\ David.ludlow@uwe.ac.uk
}

\begin{abstract}
Educational services provided to various stakeholders need to be actively developed to accommodate the diversity of learning models and to get the advantages of available resources (e.g. data) in smart cities governance. Despite the substantial literature on smart cities, for Technology-Enhanced Learning (TEL) and its related domains such as learning analytics and big data, little effort has been given to the creation of connectivity to smart cities governance to meet stakeholders' demands, even though this connection may generate various challenges arising from conflict of interests between stakeholders and organisations. This paper proposes a structural framework for successful application of smart learning environments in the context of smart city governance. It reflects on selected challenges and proposes some future directions.
\end{abstract}

\section{CCS Concepts}

Software and its engineering $\rightarrow$ Software organization and properties $\rightarrow$ Software system structures $\rightarrow$ Software architectures - 3-tier architectures.

\section{Keywords}

Smart Learning Environment; Technology-enhanced learning; eLearning; Smart City Governance; Open Participatory Planning; Learning Analytics; Big data.

\section{INTRODUCTION}

Educational organisations as well as other community institutions such as business and governments are in the core of a continuously changing world in terms of its technologies, business, legislation and practices. A massive literature exists in smart cities, e-learning/Technology-Enhanced Learning (TEL) and its related domains such as learning analytics and big data, however a little effort has been given to create balance between these domains to meet various demands and maintain successful experience for different stakeholders. Bringing the previouslymentioned domains (i.e. smart cities and TEL) together may lead to various challenges caused by conflict of interests of stakeholders, organisations, etc. This paper investigates the

Permission to make digital or hard copies of all or part of this work for personal or classroom use is granted without fee provided that copies are not made or distributed for profit or commercial advantage and that copies bear this notice and the full citation on the first page. Copyrights for components of this work owned by others than ACM must be honored. Abstracting with credit is permitted. To copy otherwise, or republish, to post on servers or to redistribute to lists, requires prior specific permission and/or a fee. Request permissions from Permissions@acm.org.

UCC '16, December 06-09, 2016, Shanghai, China

(C) 2016 ACM. ISBN 978-1-4503-4616-0/16/12 ..\$15.00

DOI: http://dx.doi.org/10.1145/2996890.3007859 potential of successful applications of smart learning environments in the context of smart cities emerging technologies with further focus on smart city governance.

On the one hand, e-learning/TEL is developing rapidly due to various reasons such as the emergence of new technologies (e.g. cloud computing and augmented reality) and the innovative application of these technologies in learning and teaching which has led to develop and identify new learning models such as connectivism [1]. In addition, TEL can be considered as an umbrella that lumps together two rich domains: learning and technology. Consequently, factors deriving changes are complicated and stemming from different categories including learners, institutions, community and technology.

On the other hand, smart cities is another wide domain that encompasses the management of an entire city through embedded technologies that monitor, track and integrate people, infrastructure, communities, health, education and other services. Moreover, smart cities is highly coupled with a list of recent technologies and innovations such as Internet of Things (IoT) because smart cities is developed, deployed and maintained with the help of IoT [2], cloud computing and wearable/environmental sensors [3]. The variety of smart cities components indicates to the complexity of its structure since it includes the following components: (i) smart environment e.g. energy management, (ii) smart governance e.g. infrastructure, (iii) smart communication e.g. identity communication, (iv) smart commerce e.g. finance and (v) smart mobility e.g. transport [2].

Smart cities and TEL overlap in many concerns such as: data, processes, regulations and most importantly the goal of providing optimised services based on the collected stakeholders' data $[4$, 5]. The rest of this paper is organised as follows: section two reviews the related work in e-learning as well as smart cities, section three introduces the proposed abstract framework that combine e-learning and smart cities to enhance learning services, section four emphasises some of the consideration and challenges to be tackled and finally section five draws certain conclusions and future work.

\section{RELATED WORK}

This section reviews the latest related research in TEL and smart cities from a general perspective and in relation to data concerns.

\subsection{Technology-Enhanced Learning Artefacts}

In this context artefact is used to refer to systems, models or frameworks. TEL artefacts are mostly dominated by certain aspects such as data or content management. For instance, 
Learning Object (LO) model is a content-oriented model while others such as Khan e-Learning Framework is a theoretical model that lists the generic dimensions of e-learning [6]. This section reviews a list of these related artefacts. First, LO is one of the core e-learning model that exists in most of other TEL artefacts such as Learning Management Systems (LMS) and IMS Learning Design (IMS LD). LO refers to any digital entity that may be used for learning, education or training [7]. LO is composed of learning objectives, a unit of instruction to teach these learning objectives, a unit of assessment to measure objectives achievement and metadata to describe the object, its content and reuse process [8]. Different metadata initiatives emerged to promote LOs discoverability by specifying which LO characteristics (e.g. title and language) should be described and vocabularies used for describing them. Examples on such initiatives include: IEEE LOM, IMS Learning Resources Metadata and Dublin Core Metadata Initiative. Yet LO limitations include: (i) contentoriented, (ii) its process is vaguely/implicitly cemented into LO content, (iii) the required trade-off between LO granularity and inter/inter-contextual reusability [9] and (iv) lack of wellstructured representation of learning issues [10] which limits its pedagogical value.

Second, Learning Management Systems (LMS) are online portals that connect different roles (e.g. learner and instructor) and provide mechanisms for classroom materials/activities to be accessible, used and shared within flexible communication environment [11]. LMSs are useful in educational context because of their various capabilities to facilitate learning and teaching [12] and their adoption flexibility. But most LMSs have been criticised as they support linear pedagogy (i.e. repetitive instructions are given as answers to problems). In addition, LMSs are: built around 'module' concept which makes it difficult to introduce flexible e-learning models such as social or informal learning models, turned to be complex and misleading environments and not generic to the extent that they can accommodate a wide range of e-learning models [13].

Third, Responsive Online Learning Environment (ROLE) is a Cloud Learning Environments (CLE) developed to help learners avoid difficulties in allocating suitable resources that are semantically described [14]. ROLE adopts semantic technology to model learners and their preferences, learning resources, learning domain and lexical-oriented concerns. Yet, ROLE framework does not comprehensively capture the learning domain. Learning is not only about suggesting proper resources or peers, it is an ongoing process that changes learner's behaviour, attitude, believes and knowledge status [15]. Also, ROLE is limited to selfregulated learning-oriented approaches and did not address cloudrelated concerns such as cross-platform in order to get the real benefits of cloud (e.g. scalability).

Fourth, additional cloud-based learning environments (e.g. [16]) have been developed yet they are mainly limited to infrastructure issues such as scalability. They also lack the potential of enhancement that can be brought to learning by cloud such as the ability to: (i) utilise effective recommendation or prediction techniques based on the large amount of data available or (ii) process complex learning models based on the huge resources available.

Finally, the enormous increase in the amount of data published online has led to the emergence of 'learning analytics'. Learning Analytics (LA) refers to the process of developing actionable insights through problem definition and the application of statistical models and analysis of data [17]. LA could be useful as they allow: individual learners to reflect on their achievements and patterns of behaviour, predict students who need further support, teachers to plan actions (e.g. supportive interventions) and administrators to take decisions [18]. LA seems promising yet it faces serious criticism in terms of what success it can bring to learning ${ }^{1}$. In addition, the scope of data captured is not sufficient and needs to be amplified so valuable conclusions can be deduced from analysis. Consequently, privacy, trust, data ownership, ethics, confidentiality and security will be significantly central concerns for all stakeholders. This may work as a barrier as the current legal systems are immature in relation to the previouslylisted concerns [19, 20]. Recent surveys (e.g. [21]) show the modest application of LA in UK educational sector and alludes to the institutions unpreparedness.

\subsection{Smart Cities}

A smart city should perform well in the following six wellestablished fields ${ }^{2}$ or characteristics [22]: (i) smart economy such as innovative spirit and entrepreneurship, (ii) smart mobility such as local accessibility, (inter-)national accessibility and availability of ICT infrastructure, (iii) smart environment such as environmental protection, sustainable resource management and pollution, (iv) smart people such as level of qualification, affinity to lifelong learning, social and ethnic plurality and participation in public life, (v) smart living such as cultural facilities, health conditions and education facilities and (vi) smart governance such as participation in decision-making, public and social services and political strategies and perspectives.

Given the essential interconnectedness of urban issues, these individual elements of the smart city can only be properly considered in a holistic framework. Consequently, a city can be smart when investments in human and social capital and traditional and modern communication infrastructure fuel sustainable economic growth and a high quality of life, with a wise management of natural resources, through participatory governance [23]. Indeed smart city governance building on principles of integrated and participative decision-making is central to the definition and delivery of each of the smart city attributes identified above. Smart city governance delivered by spatial planning defines the frameworks in which socio-economic and environmental political objectives supporting sustainable mobility, environmental enhancement and economic growth are fully considered in a sustainable and integrated assessment framework, and implemented on the basis of participative decision-making with stakeholder engagement.

Certain complexities arise from urban territorial governance that reflect the interconnected social, economic and environmental challenges. These complexities have supported a drive for integration and coordination of effort of the multiple agencies with specific sectoral responsibilities (social, economic and environmental). Another consequence of these complexities is the drive for integration initiatives by planning agencies representing different levels of governance from local to EU. Effective integrated urban governance, even though the effort continues, has proved to be a major challenge, and indeed a challenge too great for expert resolution alone. Accordingly, top-down expertise operating in integration frameworks of cross-sectoral planning teams have increasingly sought the assistance of all stakeholders

\footnotetext{
${ }^{1}$ https://groups.google.com/forum/\#!msg/learninganalytics/HdEvcl6 2MA /sb43vonnLhsJ

2 http://www.smart-cities.eu
} 
in a coalition of open governance that strives to respond effectively to the societal challenges of our time.

Out of these challenges has arisen the agenda of open governance and co-production of urban solutions [24]. The question for urban governance is thereby extended from concerns to create a more integrated management of the territory, which has dominated the transformation agenda for a generation, to a new emphasis on the means by which more participatory engagement can be achieved. In this new landscape of integrated and participatory urban governance opportunities to harness innovative social and technology solutions, derived directly from bottom-up engagement in the community, are driving expectations of a more effective policy implementation supported by the new legitimacy of the stakeholder coalition and the political capital of the community [25].

The interplay of social and technological innovation is transforming governance of our cities, as communities are demanding more active engagement in the planning of their communities and the visioning of the future city. The old order of expert master planning is transforming towards bottom-up community and neighbourhood planning supported by "mass localism" as a means to help small communities solve big social challenges [26]. At the same time technological innovation is providing new means of community engagement supporting participation in planning as well as the potentials for the definition and delivery of more integrated solutions. The dynamic of social and technological innovation is defining a new smart city governance addressing the complex challenges of urban planning and governance and simultaneously transforming the governance model in fundamental ways [27].

The above-mentioned provides insight into the potential beneficial linkages between research and development activity in the framework of technology enhanced learning and that of smart city governance. This is particularly evident in the context of open and participatory governance viewed as essential to the development of effective and democratic city planning, where research and development activity is responding to the new dynamic of social and technological innovation, to secure more effective means of stakeholder engagement in the decision-making process.

The Mobility Explorer developed by the EU funded urban API project (FP7 2011-2014) provides one exemplar of the ways in which the interplay of social and technological innovation offers new opportunities to support more effective decision-making and urban governance. The potentials of the Mobility Explorer also raise new challenges for participatory governance and effective in stakeholder engagement, and pose questions regarding the potential of smart learning environments to offer new enhanced stakeholder engagement solutions supporting smart city governance.

The Mobility Explorer utilises mobile phone data to track individual mobility within the urban environment. Analysis of this data in combination, disaggregated for socio-economic variables, and according to different time references provides a powerful understanding of socio-economic activity in the city. City planners have full understanding of every aspect of the spatial structure of cities, but know little about the socio-economic dynamic of the city that inhabits this physical form. This relationship between space and society is fundamental to effective urban planning, particularly in regard to the use and performance of urban space, interventions in urban form and their outcomes, and the modelling of ideal development solutions according to various political priorities. At present there is no framework or specification of the means of stakeholder engagement in the specification of Mobility Explorer solutions, nor the opportunities that may be realised to secure more effective engagement in this process as a consequence of the application of technology enhanced learning.

\subsection{Lessons Learnt from Literature Review}

The above-conducted review reveals that smart cities platforms and artefacts generate a heterogeneous amount of data that can be utilised to enhance learning services supporting enhanced participatory urban governance. However, no theoretical or practical attempts are found in the literature to establish effective links between TEL and smart cities. Learning and teaching are evident examples of very rich services that cannot be easily improved due to various reasons including the variety of these services and the different perceived interpretation/value of such services by stakeholders. One essential aspect here is the data. In this context, data are not limited to either learning contents or data extracted from monitoring technologies. Data extends beyond that to include plethora of social data coming from social media platforms, government data, industrial partners, surveys, health organisations, etc. Available data need to manipulated before combining different sources together because each source provide different value and context for its data which impact the decisions made based on data. Also, there should be a clear investigation for stakeholder's trust, privacy, confidentiality and security concerns in relation to the educational context. The proposed framework, presented in the next section, aims to handle such issues.

\section{THE PROPOSED FRAMEWORK}

The proposed framework aims at establishing an effective link between the TEL domain and smart cities domain from general perspectives with certain focus on data perspective in view of: (i) data importance to learning and (ii) the scope of this research that cannot cover all aspects in detail. To do so, a clear conceptualisation for both domains should be drawn including the constituent components of each domain and the potential benefits each domain can bring to the other. Smart Learning Environment includes the following three wide concerns: (i) stakeholders which includes learners, instructors, advisors and parents, (ii) technology which refers to infrastructure, platforms, tools and other technologies available for learning and (iii) institution which is a wide conceptualisation that covers the following aspects: management, ethics, support, evaluation, policy, quality, business model, goals and learning/teaching/research strategies. Figure 1 demonstrates the two domains along with their constituent components and examples (i.e. expressed by arrows) on the interaction between these components. Smart city governance provides the overarching focus for decision making that defines and delivers all other smart city components including mobility, environment, economy and society.

Additionally, the proposed smart learning environment aims to encapsulate all learning activities undertaken by a given learner, organisation or community throughout the course of his/her life with the aim of improving knowledge, skills and competences within a personal, civic, social and/or employment-related perspective. This is referred in [28] as lifelong learning. Although lifelong learning can be interpreted differently in different contexts (e.g. [29]), it has been used in this research to refer to the above-mentioned definition. The above-explained conceptualisation for both domains should lead us to define the potential benefits each domains can bring to the other. Smart 
cities, for example, have a significant amount of data that if properly utilised can assist in the application of learning services to the enhanced engagement of stakeholders in the processes of urban governance and decision making.

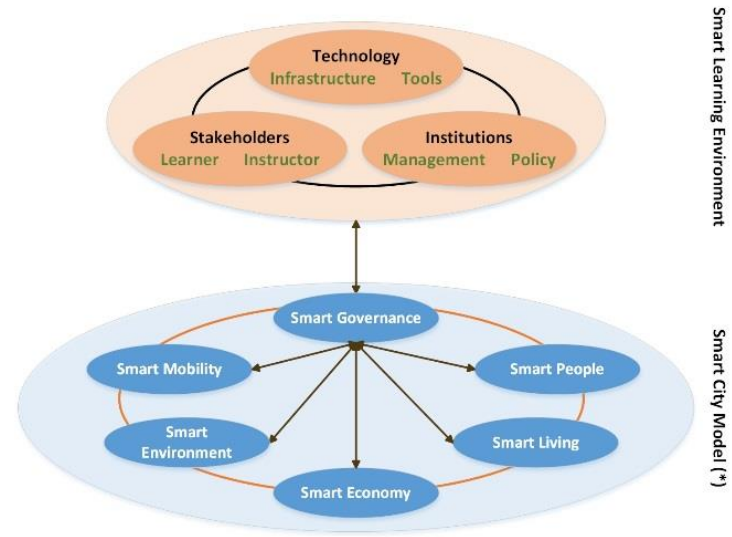

(*) http://www.smart-cities.eu/

\section{Figure 1. Smart Learning Environments in the Context of} Smart Cities

All of this requires proposing a framework that maintains the link between these components to achieve the overall goal of this paper (i.e. enhancing learning services provided to various stakeholders in the context of smart cities governance). An intrinsic part of this framework is the data captured by smart cities components (e.g. sensors), institution and stakeholders (e.g. learners). From the learning technology perspective, the type of data gathered differs by institution and by purpose or application yet generally it includes information about users' accessed contents and activities, assessment results and so on. Such data do not reflect the depth of the learning services and consequently its enhancement potential is limited. Nonetheless, expanding the scope of data to cover data coming from smart cities platforms and tools in addition to learning data raises various concerns. First, since the source of data matters it is essential to handle captured data according to its source. For instance, data coming from GPS and sensors about learner movements are quite dynamic, so they might be useful in guiding learners throughout ongoing activities or short-term goals.

Second, the flat structure is no longer valid for such a heterogeneous amount of data. Data can belong to personnel, educational institutions or coming from smart cities artefacts. Hence we introduce the concept of data hierarchy to refer to different levels of data that can be useful in manipulating security, confidentiality, privacy and ownership concerns. Third, captured data significance varies from time to time so we introduce the concept of data lifetime. This is not a simple state to tell if this data construct is valid or not valid. It is more of a flexible weight (ranging from 0 to 1 ) given to each data construct. For instance, if learner goals are current and under investigation then the lifetime value for this data construct should tend towards the maximum (e.g. $0.87,0.95$ or 1 ). This value is not deduced easily, it is calculated based on the context of that particular activity e.g. based on the social interactions with peers. Fourth, this leads to adopt the concept of perceived value of data, presented in [30].

This stems from the subjectivity of the perceived value of a certain data construct. For instance, the same values of a student goal, marks or other data construct may be perceived as positive, neutral or negative. This depends on a set of factors including decisions to be made, activity time, context, data accuracy, nature of data captured (e.g. quantitative or qualitative) and so on. Figure 2 explains the proposed framework for the smart learning environment that can work in the context of smart city governance. It is composed of the following four layers: learning manager, data manager, organisation manager and technology manager. First, Learning Manager Layer is composed of the following two components:

- Learning Planner that provides a user-centric approach to plan learning. This component is designed mainly for student to plan their learning but their plans can be viewed, modified, enriched with further information or receive recommendations from instructors, advisors, admin staff, parents

- Data Controller that allows stakeholders, especially learners, to review their models in the system. This includes what is modelled about them, who can use their models and how. This is an extension of the old concept Open Model and is gaining more interest throughout recent research projects such as Hub of All Things IoT project $^{3}$.

Second, Data Manager Layer is composed of the following four components:

- Data Merger that is responsible for collecting data from different sources and making sure that captured or merged data fulfils the data qualities identified in ISO 25012 such as traceability, currentness and precision.

- Data Hierarchy that manages the organisation of data in a suitable hierarchy to avoid flat-data structure adopted in most of the current artefacts. This allows the provision of different permissions to different data constructs.

- Data Perceived Value that deduces to what extent this particular data construct matters in a certain activity, process or transaction.

Third, Organisation Manager Layer is composed of the following four components:

- Business Model that represents the successful operation of the organisation including sources of revenue, customers, products/services and various financial concerns.

- Organisation Capacity that interprets the organisation's view on ethical, legal and related concerns. Moreover, it links them with capacity such as research, learning and teaching strategies.

- Business Goals that permits statement of the organisational goals and objectives as formally as possible.

- Community Relations where organisations express their proposed mechanisms to interact with communities and share data/information without exposing sensitive information to unnecessary stakeholders (e.g. competitors) which might lead to loss of business.

\footnotetext{
${ }^{3}$ http://hubofallthings.com
} 
Fourth, Technology Manager Layer is composed of the following three components:

- Infrastructure that manages hardware, middleware and related infrastructure and platforms (e.g. cloud, serviceoriented architecture) required to provide learning services.

- Tools that manages the use of educational tools such as learning management systems, web 2.0 tools and other personal learning environment tools.

- Technology Handler that track all actions and transactions occurred within the framework to report and failure/incomplete transaction. It allows to capture the quality of the services provided to stakeholders.

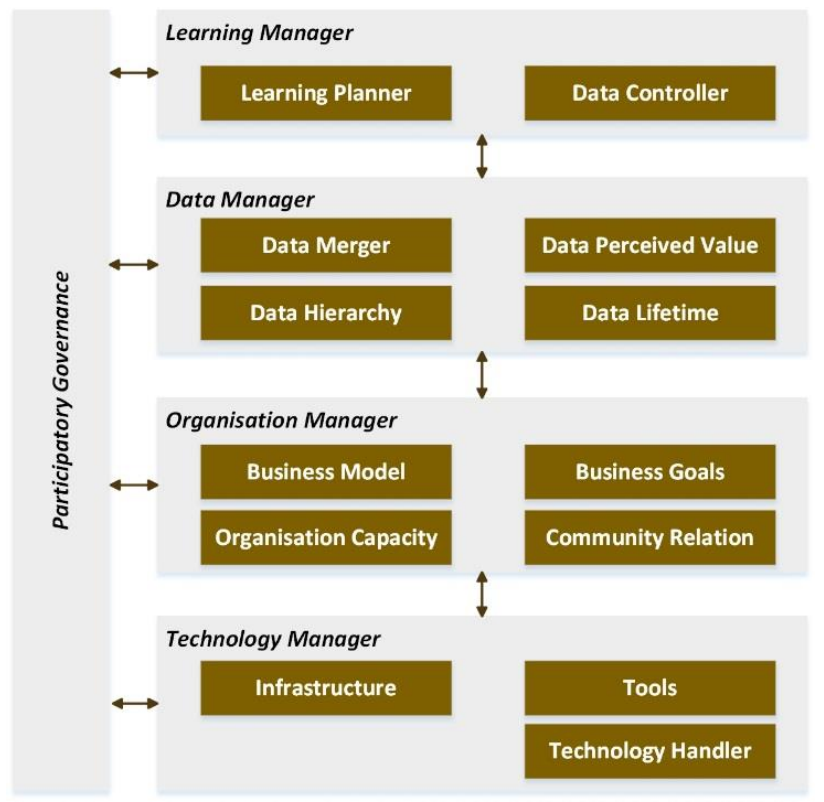

Figure 2. The Smart Learning Environment Framework

\section{DISCUSSION}

It is apparent from the above-proposed framework how smart city governance artefacts have the potential to improve learning services provided to stakeholders. Smart city governance utilises networked infrastructure to enhance the efficiency of a wide range of services and enable social and cultural development. It is also linked with/driven by various business and industrial concerns which allows effective implementation of certain learning models such as learning by doing, authentic learning and self-directed learning. The framework design is driven by smart city governance principles such as the participatory manner of sharing data. However, this requires a significant stakeholders' awareness which cannot be conveyed or managed through a simple Terms and Conditions page that is commonly used in the current software systems/services model.

As a future work, the instantiation of the proposed framework needs to be well-investigated to handle the following challenges: (i) the tangled relationship between its components as they are very dynamic, (ii) the real barriers such as the readiness of governance institutions for such learning environments, (iii) the immature legal systems that are not sufficient to respond to stakeholders concerns and (iv) the perceived barriers such as privacy, security and trust. In addition, the successful implementation of such framework needs a sufficient data set/case study to test and provide valuable conclusions. This can be resolved, at least partially, through liaising with recent initiatives/research projects to effectively test the instantiated framework. Finally, smart city governance learning environments are expected to further enrich smart cities artefacts with invaluable information that can be useful in forming a better society. It will allow government agencies to direct TEL towards research and teaching activities based on clearly-stated community needs.

\section{CONCLUSION}

This paper explains how smart learning environments can be applied in the context of smart city governance processes. It shows how the link between the two domains is missing or has not been investigated to sufficient extent, so far. Hence, we propose a framework for smart learning environments that needs to be instantiated and tested in real life scenarios, as mentioned in the previous section. The proposed framework hides many details under its components. For instance, learning planner should be linked with learning strategies such as the learning outcomes, but it is challenging to comprehend all detail in such a conceptual framework. The above plan for future work will be further elaborated before the actual prototyping in order to reassure the potential rewards for participatory and open city governance in securing more sustainable cities.

\section{REFERENCES}

[1] R. Hammad, M. Odeh and Z. Khan, "Towards A generic requirements model for hybrid and cloud-based e-learning systems," in The IEEE 5th International Conference on Cloud Computing Technology and Science (CloudCom), Bristol, UK, 2013, pp. 106-111.

[2] S. Ijaz, M. A. Shah, A. Khan and M. Ahmed. Smart cities: A survey on security concerns. International Journal of Advanced Computer Science and Applications 7(2), pp. 612-625. 2016.

[3] Z. Khan, Z. Pervez and A. Ghafoor. Towards cloud based smart cities data security and privacy management. Presented at Utility and Cloud Computing (UCC), 2014 IEEE/ACM 7th International Conference On. 2014, .

[4] R. Hammad, M. Odeh and Z. Khan, "Towards a model-based approach to evaluate the effectiveness of e-learning," in 9th European Conference on IS Management and Evaluation ECIME, UK, Bristol, 2015, pp. 111-119.

[5] D. POPESCUL and L. D. RADU. Data security in smart cities: Challenges and solutions. 20(1), 2016. . DOI: 10.12948/issn14531305/20.1.2016.03.

[6] B. H. Khan. Managing E-Learning: Design, Delivery, Implementation, and Evaluation 2005.

[7] Learning Technology Standards Committee. IEEE standard for learning object metadata. Learning Technology Standards Committee. 2002. 
[8] D. A. Wiley. Connecting learning objects to instructional design theory: A definition, a metaphor, and a taxonomy. 2003. Available: http://186.113.12.12/discoext/collections/0309/0001/02740001.pd f.

[9] S. Currier and L. M. Campbell. Evaluating 5/99 content for reusability as learning objects. Very Informal Newsletter on Library Automation (VINE) 35(1/2), pp. 85-96. 2005. . DOI: $10.1108 / 03055720510588533$.

[10] N. Friesen, "Three objections to learning objects and elearning standards," in Online Education using Learning Objects, 1st ed., R. McGreal, Ed. London: Routledge, 2004, pp. 59-70.

[11] J. Squillante, L. Wise and T. Hartey. Analyzing blackboard: Using a learning management system from the student perspective. Mathematics and Computer Science Capstones La Salle University Digital Commons2014.

[12] S. AbuShaban and R. Hammad, "Evaluating the use of WebCT in teaching at the islamic university of gaza," in The 4th Conference on E-Learning Applications at the American University, Cairo, Egypt, 2006, .

[13] K. Logan and T. Neumann. Comparison of blackboard 9.1 and moodle 2.0. Learning Technologies Unit. University of London, London, UK. 2010.

[14] A. Mikroyannidis. "A semantic framework for cloud learning environments," in Cloud Computing for Teaching and Learning: Strategies for Design and Implementation, L. Chao, Ed. 2012, .

[15] D. Schacter, D. Gilbert and D. Wegner, Psychology. New York: Worth, 2011.

[16] S. M. Butt. Cost effective hybrid cloud framework for higher education. 2013.

[17] A. Cooper, "CETIS Analytics Series Volume 1, No 5: What is Analytics? Definition and Essential Characteristics," Cetis White Paper, vol. 1, 2012.

[18] S. Powell and S. MacNeill. Institutional readiness for analytics. CETIS Analytics Series 1(8), pp. 1-11. 2012. Available: http://publications.cetis.ac.uk/2012/527.

[19] G. Siemens. Learning analytics: The emergence of a discipline. American Behavioural Scientist 57(10), pp. 1380-1400. 2013. . DOI: 10.1177/0002764213498851.
[20] S. Buckingham Shum, "LEARNING ANALYTICS: Policy brief," UNESCO Institute for Information Technologies in Education, Moscow, 2012.

[21] B. Newland, L. Martin and N. Ringan. Learning analytics in UK HE 2015: A HeLF survey report. 2015. Available: http://eprints.brighton.ac.uk/15699/1/HeLFLearningAnalyticsRep ort2015.pdf.

[22] G. C. Lazaroiu and M. Roscia. Definition methodology for the smart cities model. Energy 47(1), pp. 326-332. 2012.

[23] A. Caragliu, C. Del Bo and P. Nijkamp. Smart cities in europe. Journal of Urban Technology 18(2), pp. 65-82. 2011. . DOI: 10.1080/10630732.2011.601117.

[24] European Commission (EC), "A vision for public services," Directorate-General for Communications Networks, Content and Technology, EU, 13/06/2013. 2013.

[25] G. Misuraca. Envisioning digital europe 2030: Scenarios for ICT in future governance and policy modelling. European Foresight Platform.-2012.-C 632012.

[26] L. Bunt and M. Harris. Mass Localism: A Way to Help Small Communities Solve Big Social Challenges: Discussion Paper 2010 .

[27] EC Expert Group on Public Sector Innovation, "Powering european public sector innovation:Towards A new architecture," European Commission, Tech. Rep. EUR 13825 EN, 2013.

[28] European Commission (EC). Making a european area of lifelong learning a reality. European Commission, Brussels, Belgium. 2001.

[29] D. N. Aspin and J. D. Chapman. Lifelong learning: Concepts and conceptions. International Journal of Lifelong Education 19(1), pp. 2-19. 2000.

[30] G. C. Parry, S. A. Brax, R. S. Maull and I. C. Ng. Operationalising IoT for reverse supply: The development of usevisibility measures. Supply Chain Management: An International Journal 21(2), pp. 228-244. 2016. 